\title{
A CONSTITUCIONALIZAÇÃO E A REFUNDAÇÃO DA TEORIA DO DIREITO: NOVOS DILEMAS
}

\section{THE CONSTITUTIONALIZATION AND RE-FOUNDATION OF LAW THEORY: NEW DILEMMAS}

\author{
Luana Renostro Heinen* \\ Marcel Mangili Laurindo**
}

\begin{abstract}
Resumo: O formalismo predominou na Teoria do Direito até o final do século XIX. Com a constitucionalização do Direito vivenciada após a Segunda Guerra Mundial ocorreram mudanças significativas na Teoria do Direito, pois o direito se tornou cada vez mais dúctil, a distinção entre princípios e regras adquiriu centralidade. A proposta do artigo é descrever essas mudanças e problematizar os novos dilemas que se apresentam à Teoria do Direito após a constitucionalização: o subjetivismo na decisão judicial e a permeabilidade excessiva do Direito diante da ampliação da complexidade social. Discute-se, ainda, como a Teoria do Direito tem buscado lidar com esses novos desafios - o subjetivismo da decisão tem sido enfrentado por meio de modelos hermenêuticos e modelos de constrangimentos institucionais, já diante da permeabilidade do direito, teóricos como Niklas Luhmann afirmam a necessidade da manutenção de sua autonomia.
\end{abstract}

Palavras-chave: Teoria do Direito; Formalismo; Direito Dúctil; decisão judicial.

\begin{abstract}
Formalism predominated in the Theory of Law until the end of the 19th century. With the constitutionalisation of the Law experienced after World War II, significant changes occurred in the Theory of Law, as law became increasingly ductile, the distinction between principles and rules acquired centrality. The purpose of the article is to describe these changes and to problematize the new dilemmas that are presented to the Theory of Law after the constitutionalisation: subjectivism in the judicial decision and the excessive permeability of the Law before the amplification of the social complexity. It is also discussed how Law Theory has tried to deal with these new challenges - the subjectivism of the decision has been confronted through hermeneutic models and models of institutional constraints, already before the permeability of the law, theoreticians like Niklas Luhmann affirm the need to maintain their autonomy.
\end{abstract}

Keywords: Theory of Law; Formalism; Ductile Law; judicial decision.

\footnotetext{
* Doutora em Direito pela UFSC, Professora Adjunta da Universidade Federal de Santa Catarina. Contato: luanarheinen@gmail.com.

** Defensor Público do Estado de Santa Catarina. Mestre em Sociologia Política e Doutorando em Direito pela UFSC. Contato: mangili84@gmail.com
} 


\section{INTRODUÇÃO}

A proposta desse artigo é compreender como a Teoria do Direito se alterou após a constitucionalização do Direito vivenciada no século XX. No contexto de pluralidade política e extrema complexidade, o Direito deixa de ser lugar de certezas ou de respostas corretas, para se transformar em um Direito dúctil (como defende Zagrebelsky, 2011). O formalismo deu lugar a uma nova Teoria do Direito que se depara com a distinção entre princípios e regras. Ocorre que, nesse contexto, novos dilemas se apresentam ao Direito: o do subjetivismo na decisão judicial e da permeabilidade excessiva do Direito diante da ampliação da complexidade social, que faz com que a autonomia do Direito seja colocada em xeque.

A primeira parte do artigo é dedicada a expor o que representou a Constitucionalização do direito vivenciada na maioria dos países ocidentais após a Segunda Guerra com a consagração dos direitos fundamentais como fundamento infundado do sistema jurídico. O resultado desse processo é apresentado como a consagração de um patrimônio comum da humanidade para a afirmação da cultura dos direitos humanos, da limitação do poder e da convivência civilizada. Na segunda parte, apresentam-se as características do formalismo jurídico que predominou na Teoria do Direito até o final do século XIX e passou a ser questionado com a constitucionalização do direito. A terceira parte é dedicada a expor uma releitura da Teoria do Direito, ressignificada pela constitucionalização, a partir da obra do jurista italiano, Gustavo Zagrebelsky, a teoria do direito dúctil, que abandona a rigidez para adotar uma estrutura de valores e princípios que não é absoluta. Central nessa nova teoria do direito é a distinção entre princípios e regras, discutida em tópico próprio no texto. A nova teoria do direito se depara com novos dilemas que são objeto de discussão no último tópico do artigo, de modo a tentar compreender como se tem tentado responder a esses novos dilemas.

\section{CONSTITUCIONALISMO E PATRIMÔNIO COMUM}

Os totalitarismos das décadas de 1930, especialmente na Alemanha e na Itália, assolaram a Europa e mostraram a força do radicalismo sem limites. Em sua autobiografia, o literato austríaco Stefan Zweig, judeu que se exilou no Brasil, relata o clima do período antes da ascensão de Hitler ao poder: os europeus não podiam acreditar que suas sólidas instituições estariam sujeitas a ruírem de tal maneira ${ }^{1}$. O 
A constitucionalização e a refundação da Teoria do Direito: novos dilemas

totalitarismo mostrou, como explica Pietro Costa, “[...] a força terrível do poder, a fragilidade do indivíduo, a inadequação das salvaguardas até aquele momento estabelecidas" (COSTA, 2010, p. 254). Como uma proposta de solução a esse problema, ou seja, um reforço para as garantias dos indivíduos, surgiu o constitucionalismo do pós-guerra.

As raízes do constitucionalismo do segundo pós-guerra estão, segundo Pietro Costa (2010), nos projetos antitotalitários dos anos de 1930, como a Constituição de Weimar e a Constituição espanhola de 1931. O constitucionalismo floresceu abandonando o formalismo kelseniano e adotando como base do ordenamento a pessoa - "o centro de imputação de uma multiplicidade de direitos diversos". Nessa nova cultura jurídica que se instaura, democracia e direitos são necessariamente complementares. A democracia se redesenha como "[...] uma ordem centrada sobre a pessoa e sustentada pela convicção de que apenas a atribuição a todos os cidadãos de iguais direitos permite a eles uma completa realização humana.” (COSTA, 2010, p. 255).

Ao reforçarem a posição central do indivíduo, os direitos demonstram seu caráter antitotalitário. Mas, como explica Pietro Costa (2010), não basta falar de direitos para se evitar um retrocesso. É preciso ir além e “[...] destacar os direitos da atração fatal exercida sobre eles pelo Estado." (COSTA, 2010, p. 255). Iniciou-se, então, uma crítica da soberania estatal e uma nova maneira de pensar a posição dos direitos nos ordenamentos.

Consagrados nas novas cartas constitucionais, os direitos dos indivíduos passam a ser tidos como fundamentais" : ocupam a posição singular de "fundamentos infundados" da nova ordem. Oferecem o fundamento da nova ordem, mas também a destinação de sentido, ou seja, tem função estática e dinâmica, pois fecham o sistema (fundamento), mas também prescrevem como o sistema deve avançar. Daí provém as discussões sobre a realização dos direitos, sobre o caráter programático das constituições, sobre a necessidade de efetivar esses direitos e, posteriormente, a defesa de uma Constituição invasora que deve estar presente em todo o sistema.

Com a promulgação da Constituição Federal de 1988, o Brasil inaugurou uma nova ordem jurídica e pode-se dizer que ingressou na cultura do constitucionalismo. Trata-se de um momento crucial na história jurídica e política do país, porque a Constituição não se limita a um conceito dogmático sobre a hierarquia de 
fontes do direito, mas está ligada à emergência da vontade popular na condução da vida política e implica a adoção do Estado Democrático de Direito.

O Brasil - de maneira semelhante a outros países, europeus (Alemanha, Itália, Portugal, Espanha e Grécia) e também latino-americanos (Argentina, Uruguai e Chile) - saiu de um período de regime autoritário e a promulgação da Constituição de 1988 marcou a emergência da vontade popular na condução da vida política do país.

A adoção de uma Constituição democrática e pautada na defesa dos direitos fundamentais também se relaciona com outro fenômeno do constitucionalismo contemporâneo, para alguns conhecido como pós-positivismo (BARROSO, 2013) e, para outros, chamado de Neoconstitucionalismo ${ }^{3}$ (COMANDUCCI, 2003). Essa tendência do constitucionalismo contemporâneo, surgida principalmente após a Segunda Guerra Mundial, tem como características principais: o reconhecimento pleno da força normativa (cf. HESSE, 1991) da Constituição, a expansão da jurisdição constitucional e a nova interpretação constitucional, pautada nos princípios e na técnica de ponderação (cf. BARROSO, 2007). Paolo Comanducci (2003) enfatiza que, enquanto teoria, o Neoconstitucionalismo se propõe a descrever o sistema jurídico típico do Estado Democrático de Direito que se desenvolveu com o fenômeno da constitucionalização. Esse Estado se caracteriza por uma Constituição invasora, onipresente em todos os âmbitos do sistema por meio do catálogo de direitos fundamentais que consagra. Nesse novo modelo haveria peculiaridades interpretativas para as normas e princípios constitucionais, face às leis ordinárias. A teoria neoconstitucionalista, surgiria, assim, para conseguir explicar o fenômeno do "Estado Constitucional Democrático de Direito", para o qual o positivismo não teria mais força explicativa ${ }^{4}$.

Os problemas relacionados às possíveis revisões constitucionais pelo Parlamento foram resolvidos com cláusulas constitucionais de imutabilidade: na Itália o art. 139 da Constituição prevê a imutabilidade da forma republicana e a Corte Constitucional declarou imutável os princípios que "[...] pertencem à essência dos valores supremos sobre os quais se funda a constituição italiana." (COSTA, 2010, p. 259). No Brasil, os direitos e garantias fundamentais são imutáveis por força das cláusulas pétreas consagradas no art. $60, \S 4^{\circ}$ da Constituição Federal.

Assim, o constitucionalismo conseguiu colocar freios à manifestação do Poder Constituinte derivado, por meio da reivindicação de um caráter meta ou 
A constitucionalização e a refundação da Teoria do Direito: novos dilemas

transestatal para os princípios e direitos fundamentais, de modo a torná-los resistentes ao decisionismo da política.

Por isso, o fenômeno da constitucionalização que se seguiu ao pós-Segunda Guerra Mundial representou um marco na história político-jurídica do ocidente, uma "revolução copernicana" nas relações governantes-governados com a instituição do estado democrático de direito: de deveres dos súditos para os direitos dos cidadãos. Deu-se a emergência do que Norberto Bobbio (2004) chamou de "Era dos Direitos", em que os direitos humanos ocupam parte proeminente no debate internacional e foram positivados nos textos constitucionais, transformados, assim, em direitos fundamentais, fundadores dos sistemas jurídico-políticos de cada país.

A emergência da vontade popular somou-se à valorização dos direitos humanos. Nem sempre, no entanto, o primado da vontade constituinte do povo e a garantia dos direitos humanos estiveram juntos. Em vários momentos da tradição constitucional e política ocidental estiveram, inclusive, em lados opostos, com a afirmação de direitos humanos e inalienáveis sendo utilizada como meio de resistência (cf. HESPANHA, 2014, p. 355).

Como explica António Manuel Hespanha (2014), a fórmula encontrada para conferir espessura constitucional aos direitos humanos, permitindo sua harmonização com a vontade popular (com fundamento democrático), foi a sua positivação em direitos fundamentais.

Para Bobbio (2004), o nexo entre direitos humanos e a cidadania democrática como princípio de governança pode ser capaz de, finalmente, construir a paz. Em seu célebre texto sobre a Era dos Direitos, Bobbio (2004) ainda reconhece que a questão da fundamentação dos direitos humanos se tornou uma questão menor, devido ao reconhecimento de um consenso abrangente por meio da Declaração Universal dos Direitos Humanos de 1948, que passou a ser o lastro desses direitos. Como afirma Celso Lafer: "[...] um consensus omnium gentium sobre a relevância dos direitos humanos para a convivência coletiva" (LAFER, 2004, p. IX-X). Assim, a questão central que se coloca hoje é não da fundamentação, mas da concretização desses direitos.

Pode-se afirmar, como sustenta o jurista italiano Michele Carducci (2011; BRUNO, 2013), que a cultura dos direitos humanos, a limitação do poder e a convivência civilizada, inicialmente afirmadas como características de algumas culturas ocidentais, consagraram-se, ao menos formalmente, como o patrimônio comum da 
humanidade. O constitucionalismo é, assim, esse patrimônio comum que centraliza a ordem constitucional na pessoa humana e foi responsável por, na Europa, colocar o humanismo como espírito e propósito das instituições, além de produzir efeitos técnicos como uma nova maneira de se entender as Constituições (CARDUCCI, 2011, p. 352353).

$\mathrm{Na}$ esteira, no entanto, do que afirma Bobbio (2004), o dilema está na preservação e na realização desse patrimônio comum. A seguir apresenta-se o formalismo como caracterização da Teoria do Direito que prevaleceu até o final do século XIX para, então, discutir os novos dilemas que se apresentam a ela a partir da constitucionalização.

\section{O FORMALISMO JURÍDICO}

Não há exatamente um consenso em Teoria do Direito sobre o que caracteriza o formalismo jurídico. No entanto, pode-se apontar como características gerais da Teoria do Direito formalista a defesa de que o Direito seria completo, de que haveria uma regra para cada caso (coerência e exatidão), que essa regra poderia ser interpretada de forma clara e também uniforme.

A primeira das características é o que Bobbio (2010) chama de dogma da completude, segundo o qual o ordenamento jurídico seria capaz de fornecer ao juiz uma solução para cada caso. Como explica Bobbio (2010), esse dogma se afirma juntamente com a monopolização da produção jurídica pelo Estado, como uma forma de manter o próprio monopólio. Nesse contexto, com as codificações, afirmou-se o veredicto de que o juiz deve julgar permanecendo dentro do sistema. Com a Escola da Exegese forjou-se o fetichismo da lei: tudo estaria no Código. A completude foi criticada especialmente pela Escola do Direito Livre que afirmava que diante da existência evidente de inúmeras lacunas no ordenamento, seria necessário confiar no poder criativo do juiz. Diante das lacunas, os próprios ordenamentos passaram a prever meios de saná-las, pela autointegração (em que se recorre ao próprio ordenamento, como pela analogia) ou através da heterointegração (quando se recorre a recursos externos a determinado sistema jurídico, como ao caso do costume, direito comparado ou equidade).

A coerência e exatidão estão relacionadas à visão do direito como um sistema porque nele não existem normas incompatíveis (BOBBIO, 2010). Essa exigência nasceu no Direito Romano e já estava presente no Digesto de Justiniano. 
Modernamente, explica Bobbio (2010), passaram-se a utilizar os critérios cronológico, hierárquico e da especialidade para resolver essas antinomias, com vistas a se assegurar o dever de coerência do ordenamento. Esse dever nada mais é do que uma exigência de justiça, pois a existência de duas normas incoerentes poderia levar a soluções distintas em casos concretos semelhantes.

Já a questão da interpretação do direito para o formalismo se resolve na defesa de que ela é sempre declarativa e nunca criativa. O limite intransponível da atividade interpretativa é o texto, por isso, o formalismo recorre a métodos como a interpretação gramatical e sistemática para garantir a que a interpretação respeite a vontade do legislador (cf. BOBBIO, 2006, p. 214). Essa visão encontrava guarida em autores da Escola da Exegese e também nos defensores do dogma de que o juiz deveria ser la bouche de la loi (como o fez Montesquieu, mas também outros autores iluministas, como Cesare Beccaria, preocupado com que o juiz não extrapolasse as penalidades previstas na lei penal $)^{5}$.

O formalismo assim caracterizado, que não se confunde com o positivismo jurídico $^{6}$, foi a Teoria do Direito que prevaleceu desde o final do século XIX. Ainda que nem sempre declarada, era a teoria que sustentava, por exemplo, boa parte da dogmática jurídica - aquilo que Luís Alberto Warat (1982) chamou de "senso comum teórico dos juristas".

Com o fenômeno da constitucionalização do Direito, no entanto, essa Teoria do Direito tornou-se insuficiente para lidar com um direito que não pode se pautar mais somente na perspectiva de sistema como um sistema dinâmico no sentido defendido por Kelsen (1998), em que as normas jurídicas derivam umas das outras por sucessivas delegações de poder, mas também é preciso que o conteúdo das normas jurídicas infraconstitucionais respeite ao texto da principal norma do sistema: a Constituição.

Os novos ordenamentos do pós-guerra não representam uma total negativa da obra de Kelsen, obviamente, devem-lhe alguns pressupostos. Pietro Costa (2010) explica que eles têm uma dupla relação com a obra de Kelsen: são uma homenagem tardia a sua teoria do Estado de direito constitucional, porque as ideias de hierarquia e controle de constitucionalidade derivam do modelo kelseniano. Mas também são uma retratação do formalismo kelseniano:

para regimes que nascem sobre as ruínas dos totalitarismos não são suficientes garantias procedimentais e dispositivos formais, mas são necessários princípios substantivamente densos e comprometidos. A solução 
kelseniana das 'maiorias qualificadas' não podia, em suma, não parecer reducionista e demandava ser reforçada por uma categoria de princípios e direitos fundamentais capazes de resistir a qualquer manipulação da maioria (COSTA, 2010, p. 257).

Nesse novo sistema, a coerência passou a ser buscada tendo como referência a própria Constituição e os princípios. Os princípios surgiram, então, como a nova categoria jurídica que veio responder às necessidades substanciais que se apresentavam ao Direito.

\section{A TEORIA DO DIREITO DÚCTIL}

O jurista italiano Gustavo Zagrebelsky (2011) escreveu uma obra em que trabalha as mudanças pelas quais passou a Teoria do Direito com o constitucionalismo do pós-guerra. Trata-se do livro O direito dúctil. Lei, direitos e justiça. Apesar de ser uma obra que retrata o constitucionalismo europeu, há que se reconhecer que, pela disseminação da cultura constitucional, ela serve a explicar e tratar das transformações sofridas também por países latino-americanos, como o Brasil que, especialmente após a Constituição Federal de 1988, tem vivenciado a consagração do constitucionalismo.

O pluralismo político e o relativismo ${ }^{7}$ caracterizam as sociedades modernas ocidentais, por isso, defende Zagrebelsky (2011), não cabe à Constituição ser um projeto de vida comum pré-determinado, mas um documento que visa estabelecer as condições de possibilidade para a realização da vida plural nas sociedades modernas. A Constituição é uma plataforma de partida a partir da qual se inicia a competição para imprimir ao Estado uma orientação em um ou outro sentido, no âmbito das possibilidades oferecidas pelo compromisso constitucional (cf. ZAGREBELSKY, 2011, p. 13).

Nesse contexto é que o direito é visto por Zagrebelsky (2011) como um direito dúctil, ou seja, maleável. Para que seja viável a convivência entre a pluralidade de valores e princípios que caracterizam a sociedade moderna o direito abandona a rigidez para adotar uma estrutura de valores e princípios que não é absoluta. Somente tem caráter absoluto o meta-valor do pluralismo dos valores. Os grandes temas do direito constitucional somente podem coexistir se forem relativizados.

Além de um Direito Constitucional dúctil, Zagrebelsky (2011) defende a necessidade de uma dogmática também fluída ou líquida, capaz de agrupar esses elementos do Direito Constitucional dúctil, onde os conceitos mantenham sua 
A constitucionalização e a refundação da Teoria do Direito: novos dilemas

individualidade, porém os choques não sejam destrutivos, mas reconheçam a possibilidade e a necessidade de coexistência - esse sim o único conceito sólido: a defesa do pluralismo e da coexistência dos valores.

Assim, para Zagrebelsky (2011), a grande transformação sofrida pelo direito nesse contexto de constitucionalismo nas sociedades plurais indica a busca de concepções não absolutas. O Estado de Direito se pautava na separação dos poderes e na igualdade perante a lei, era um Estado inimigo dos excessos, que tinha como fator de estabilização a legalidade. Já no Estado Constitucional, buscam-se concepções não absolutas e a Constituição passa a ser o elemento de estabilização do sistema. Isso porque, explica Zagrebelsky (2011, p. 35), a própria lei passou a ser causa de instabilidade devido a sua pulverização (reduzida generalidade e abstração) e sua heterogeneidade, pelos mais distintos valores e princípios que expressa respondendo às inúmeras negociações - essas, resultado do confronto entre valores divergentes e até mesmo antagônicos ${ }^{8}$.

Nesse contexto de crise da legalidade, a lei deve-se subordinar à Constituição, de modo a se buscar a estabilização do sistema na Constituição. A busca de equilíbrio entre lei e direitos, entre direitos de liberdade e direitos de justiça, entre a atuação do legislador e do juiz, passa a ser uma constante.

\subsection{A DISTINÇÃO ENTRE PRINCÍPIOS E REGRAS}

A grande mudança sofrida pela Teoria do Direito, na passagem do Estado de Direito para o Estado Constitucional, segundo Zagrebelsky (2011), diz respeito à diferenciação entre regras e princípios. Os autores positivistas não tratavam dos princípios, Hans Kelsen e Herbert Hart, por exemplo, partem da existência somente das regras no sistema jurídico. Essa é, inclusive, uma das críticas centrais que Ronald Dworkin (2002) faz à Herbert Hart em seu texto "O modelo de regras" publicado em 1967 (publicado posteriormente no livro "Levando os direitos a sério" de 1977). Para Dworkin (2002) o reconhecimento da existência dos princípios, prejudica o modelo de Hart, na medida em que os princípios não dependem de validação pela regra de reconhecimento, distinguem-se estruturalmente das regras e possibilitam limitar a discricionariedade judicial. Esse desenvolvimento foi importante para Dworkin (2002) alcançar seu intento de estabelecer critérios limitadores da discricionariedade judicial. Em confronto com Dworkin, Hart (2009) defendia que na inexistência de regras ou no 
caso dos hard cases, a decisão judicial ficaria sujeita à discricionariedade.

Para Carla Faralli (2006), a distinção entre regras e princípios que é adotada pelo constitucionalismo, foi precedida pelo Direito como integridade de Dworkin, segundo o qual o direito é uma "complexa atividade de interpretação que não é deixada à discricionariedade dos juízes, mas firmemente ancorada nos princípios, fruto de um preciso desenvolvimento histórico". Ela explica que Dworkin questiona a separação positivista entre direito e moral e afirma que

não é possível reduzir os ordenamentos jurídicos a meras estruturas normativas e que, ao lado das regras (rules), existem os princípios (principles), que vão além do direito estatuído, na medida em que se referem a fins (como o bem-estar da comunidade) ou a valores (entre os quais os direitos individuais) (FARALLI, 2006, p. 4).

Para Dworkin, (2002), a distinção entre princípios e regras é de natureza lógica. As regras seriam aplicadas segundo o padrão de "tudo-ou-nada", ou seja, "[...] dados os fatos que uma regra estipula, então ou a regra é válida, e neste caso a resposta que ela fornece deve ser aceita, ou não é válida, e neste caso em nada contribui para a decisão" (DWORKIN, 2002, p. 39). No caso da regra inválida ela vai ser, inclusive, excluída do sistema. Já os princípios não estabelecem as condições de sua aplicação necessária, mas enunciam razões que conduzem o argumento em uma certa direção. Princípios podem conviver com outros princípios, no mesmo sistema jurídico, que argumentem em outra direção, o que não implica que sejam excluídos do sistema. O que determinará qual dos princípios irá prevalecer no caso concreto é seu peso ou importância - dimensão que não existe nas regras (cf. DWORKIN, 2002, p. 39ss).

Segundo Dworkin (2002), os princípios são padrões que devem ser observados por serem uma exigência de justiça ou de retidão (moral) ${ }^{9}$.

\footnotetext{
Os princípios são realidades heterogêneas em relação às [regras], mas são complementares a elas no ordenamento jurídico: as regras são válidas enquanto normas estabelecidas, e podem ser mudadas somente por força de uma deliberação, enquanto os princípios são válidos enquanto correspondem a exigências morais sentidas num período específico, e seu peso relativo pode mudar no decorrer do tempo. Os tribunais devem recorrer a estes últimos para resolver os casos difíceis (hard cases), aos quais não seria possível aplicar uma regra sem cometer uma injustiça (FARALLI, 2006, p. 5).
}

Dworkin lançou, assim, a principiologia nos anos 1960, enquanto o jurista alemão Robert Alexy a reconstruiu na década de 1970, baseando-se na jurisprudência do Tribunal Constitucional Federal alemão (cf. NEVES, 2014). Para Alexy (2008) o ponto 
decisivo na distinção entre regras e princípios é qualitativo, não de grau. Ele afirma que os princípios são mandamentos de otimização, ou seja, normas que ordenam que algo seja realizado na maior medida possível dentro das possibilidades jurídicas e fáticas existentes. Justamente por isso, podem ser satisfeitos em diferentes graus. A medida da satisfação do princípio não depende somente das possibilidades fáticas, mas também das possibilidades jurídicas. O âmbito das possibilidades jurídicas é determinado pelos princípios e regras colidentes. As regras, por sua vez, são razões definitivas, pois são normas que são sempre ou satisfeitas ou não satisfeitas. Se uma regra vale, então, devese fazer exatamente aquilo que ela exige; nem mais, nem menos. Regras contém, portanto, determinações no âmbito daquilo que é fática e juridicamente possível. Princípios são razões prima facie, enquanto as regras são razões definitivas.

A partir desse debate sobre a distinção entre princípios e regras, Zagrebelsky (2011) afirma que as leis são predominantemente regras, enquanto que as normas constitucionais sobre direitos e justiça são princípios (apesar das Constituição também conterem regras). Por isso, distinguir entre princípios e regras é distinguir entre Constituição e lei. Assim, ele aponta as seguintes características diferenciadoras: 1) somente os princípios desempenham papel constitucional (constitutivo da ordem jurídica), já as regras se esgotam em si mesmas e não tem força constitutiva; 2) a interpretação das regras depende da busca do seu significado linguístico, para obedecêlas ou não. Enquanto aos princípios se presta adesão e, por isso, deve-se buscar compreender seu ethos (o mundo dos valores do qual tomam parte); 3) as regras estabelecem critérios para as ações (como se deve ou não agir), já os princípios proporcionam critérios para se tomar posição diante de situações concretas que pareciam indeterminadas - o significado dos princípios somente se revela diante do caso concreto $^{10}$; 4) enquanto as regras são aplicadas de forma mecânica e passiva, os princípios exigem uma tomada de posição; 5) as regras são aplicáveis à maneira do tudo ou nada, enquanto os princípios conforme seu peso ou importância; 6) operam-se as regras pela subsunção (o método lógico-formal), já os princípios dependem do que Zagrebelsky (2011) chama de prudência em sua aplicação:

una actitud, una predisposición hacia soluciones dúctiles que tomen en consideración todas las razones que puedan reivindicar buenos principios en su favor. [...] Busca la respuesta más adecuada para las expectativas legítimas y, por ello, está abierto al enfrentamiento entre todas las posiciones que remiten a principios vigentes en el derecho. En los contextos pluralistas es necesario hacer "discursivo" y "persuasivo" el procedimiento a fin de 
alcanzar el punto de máxima realización de los principios en juego (ZAGREBELSKY, 2011, p. 123).

Zagrebelsky (2011) rejeita o modelo de interpretação subsuntivo do direito porque inadequado ao direito no estado Constitucional, em que o direito é dúctil e o trabalho do jurista se torna a juris prudencia, que se contrapõe à scientia juris.

O juiz nesse novo Estado Constitucional também assume nova posição. A interpretação tem uma preocupação eminentemente prática e pautada em uma pluralidade de métodos de interpretação que permitam respeitar o modelo baseado em regras e princípios. A interpretação declarativa do direito defendida pelo formalismo dá lugar a uma interpretação criativa por parte do Juiz, em que este assume pontos de vista distintos que refletem em sua atuação - isso não significa, no entanto, uma má disposição, mas o esgotamento de um quadro de princípios e valores compartilhados. Zagrebelsky (2011) rejeita a existência de uma única resposta correta que busca realizar a vontade do legislador isso porque, diz ele, a própria interpretação do texto legal gera uma pluralidade de sentidos. Essa pluralidade e falta de certeza não é uma anomalia, mas uma consequência dos sistemas jurídicos atuais que se pautam em princípios de conteúdo variável e com função dinâmica no ordenamento, em que a busca de justiça não é tida como subversão do direito, mas é admitida.

Por fim, Zagrebelsky (2011) questiona se a busca de certeza pode ser um objeto realista ou até mesmo desejável, na medida em que exigiria do legislador alterar constantemente o direito, o que se faz, segundo ele de forma silenciosa, nas salas dos tribunais e nos estudos dos juristas. No Estado de Direito, o legislador tinha posição central, já no Estado Constitucional, os juízes são os atuais "señores del derecho", pois eles reúnem todas as dimensões do direito: lei, direitos e justiça.

\section{NOVOS DILEMAS DA TEORIA DO DIREITO NO ESTADO CONSTITUCIONAL: O SUBJETIVISMO NA DECISÃO JUDICIAL E A AUTONOMIA DO DIREITO}

As mudanças na Teoria do Direito, na passagem do Estado de Direito para o Estado Constitucional, indicam, assim, um direito dúctil, mais aberto à complexidade social justamente por meio da nova categoria jurídica: os princípios.

No entanto, nesse contexto, ao menos dois grandes problemas se apresentam ao direito: uma preocupação com o subjetivismo dos juízes por um lado e, por outro, R. Fac. Dir. UFG, v. 42, n. 3, p.11-34, set./dez. 2018 
A constitucionalização e a refundação da Teoria do Direito: novos dilemas

com a autonomia do direito.

Discute-se se esses dilemas são o resultado da própria Teoria do Direito neoconstitucionalista ou de sua inadequada recepção no Brasil e, por consequência, da maneira tupiniquim de aplicá-la - que a transfere para o Brasil sem considerar a realidade para a qual foi pensada. Para o jurista espanhol Juan Antonio Garcia Amado (2007, 2010), trata-se de uma consequência da própria teoria de Alexy. Segundo Garcia Amado (2007, 2010), Alexy não distingue de forma estrutural princípios e regras; diz que a ponderação é uma técnica diferenciada de resolução de conflitos entre princípios, quando se trata de uma um meio para se justificar decisões mais ou menos arbitrárias dos juízes, por meio de exigências argumentativas menores ou invocando razões de mais difícil controle intersubjetivo. Já Lênio Streck (2013) entende que o problema diz respeito à recepção dessas teorias no Brasil. O jurista gaúcho enfatiza que a tendência ao protagonismo judicial para concretizar direitos, decorreria da inadequada recepção da jurisprudência dos valores, desenvolvida na Alemanha do Pós-Segunda Guerra Mundial.

Não é possível apontar uma causa única para esses dilemas, tanto a permeabilidade da teoria para o subjetivismo quanto sua inadequada recepção no Brasil contribuem para configurar os novos dilemas da Teoria do Direito.

É preciso considerar, ainda, como sugere José Rodrigo Rodrigues (2013), que a maneira como está estruturado nosso sistema judicial brasileiro para a tomada de decisões é significativamente pautada na pessoalidade da decisão, o que favorece o subjetivismo. Rodriguez (2013) chegou a essa conclusão após realizar uma pesquisa empírica em que concluiu que a pessoalidade da decisão judicial prevalece no Brasil entre outros motivos, porque: a) a decisão é tomada por maioria e não valoriza os argumentos no resultado final (pode haver decisões unânimes, mesmo que todos os juízes de um órgão colegiado discordem dos fundamentos); b) cada juiz tem direito de opinar; c) não há uma trama argumentativa explícita que sustente as decisões pois se valoriza mais o resultado; d) por fim, a jurisprudência se faz por súmulas e enunciados e não por meio de argumentos organizados e aplicáveis a cada caso.

Para criticar a falta de controle da decisão judicial, argumenta-se que o juiz não tem legitimidade política para ir além do texto legal, na medida em que os legitimados politicamente para legislarem são os representantes eleitos pelo povo - os membros do Poder Legislativo. Nas concepções modernas de democracia, a separação de Poderes entre Judiciário e Legislativo é, nesse sentido, tida como uma garantia. Além 
disso, afirma-se que o subjetivismo judicial gera insegurança jurídica que prejudica a previsibilidade social do direito para os agentes sociais, especialmente dos agentes econômicos (cf. RODRIGUEZ, 2011).

A tentativa de se controlar o subjetivismo dos juízes tem sido enfrentada por ao menos dois caminhos: por meio dos modelos hermenêuticos que visam reforçar o ônus argumentativo do intérprete e, de outro lado, pelos constrangimentos institucionais (cf. RODRIGUEZ, 2011).

Os constrangimentos institucionais dizem respeito aos desenhos institucionais que, para o jurista francês Michel Troper (2005), são a única maneira de se controlar a decisão judicial. Isso porque Michel Troper (2005) considera, assim como Hans Kelsen (1998), que a decisão judicial é matéria de política e a ciência do direito não pode contribuir a controlá-la (para cada questão colocada ao juiz há diferentes respostas fundadas no direito posto e a escolha é subjetiva). Dois aspectos do desenho institucional podem ser ressaltados como formas de constrangimento institucional: 1) o recrutamento dos juízes - conforme o modelo adotado pode-se favorecer uma homogeneidade da magistratura, com o objetivo de se alcançar maior congruência nas decisões, ou maior pluralidade no perfil dos magistrados (de modo que se incorporem diferentes concepções sobre o direito e sua aplicação); 2) a estrutura e os procedimentos do Poder Judiciário (a existência de um duplo grau de jurisdição e de mecanismos por meio dos quais os graus superiores possam impor suas decisões - como súmulas, enunciados de precedentes, etc) que podem também ser avaliados quanto à sua capacidade de produzir decisões congruentes (cf. RODRIGUEZ, 2011).

Para enfrentar o problema do subjetivismo na decisão judicial, a segunda proposta parte de modelos hermenêuticos que possam auxiliar na construção de regras racionais para a interpretação e aplicação das normas jurídicas. Exemplos desses modelos hermenêuticos são a proposta da Tópica de Viehwig e a Teoria da Argumentação de Alexy.

No contexto de intensa pluralidade que vivemos nas sociedades atuais, em que o direito, como afirma Zagrebelsky (2011) torna-se dúctil, no entanto, a existência de várias decisões racionais (várias possibilidades interpretativas, desde que racionais) sobre um mesmo problema jurídico não deve ser vista como destrutiva da racionalidade do direito. É importante conceber essa pluralidade a partir de uma nova perspectiva de segurança jurídica. Como afirma José Rodrigo Rodrigues (2011), a segurança jurídica 
A constitucionalização e a refundação da Teoria do Direito: novos dilemas

deve deixar de ser entendida com base em uma concepção textualista da racionalidade jurisdicional, em que a demanda por uma resposta única está relacionada com uma estratégia legislativa que privilegia textos normativos fechados. Até porquê, mesmo com textos normativos fechados, os juízes podem criar exceções para adaptá-los aos casos concretos. Na realidade atual brasileira, há muitos textos normativos abertos (principalmente com a adoção dos princípios), por isso, a segurança jurídica precisa ser compreendida não como a obtenção de uma única resposta correta ${ }^{11}$, mas preocupada com a dimensão argumentativa, o que deve ganhar centralidade é a explicitação dos argumentos por parte dos juízes (RODRIGUEZ, 2012, p. 143). A explicitação dos argumentos é que possibilitará o controle interno da decisão (dentro do direito, por exemplo, por meio do sistema de recursos) e também responderá à necessidade de legitimidade política dessa decisão (frente à coletividade).

O novo ideal de segurança jurídica, como proposto por Rodriguez (2012) enfatiza a argumentação racional, por um lado, mas também a abertura e pluralidade de respostas, enfatizando que essa pluralidade é que permite a persistência do debate. Ou seja, ainda que o debate se encerre naquele caso concreto (o que também é uma exigência feita ao próprio sistema jurídico que precisa responder às demandas que lhe são apresentadas em um período de tempo razoável), o debate persistirá para demonstrar que as decisões tomadas poderiam ter sido diferentes e que os fundamentos decisórios poderão ser alterados no futuro. A abertura possibilita ao direito fazer frente, constantemente, a novos conflitos.

Essa grande abertura do direito aos conflitos sociais e outras demandas que lhe sejam apresentadas coloca-nos, no entanto, diante de um segundo dilema enfrentado pela Teoria do Direito. A questão da autonomia do direito. Uma contribuição para lidar com esse problema se encontra na obra do jurista alemão Niklas Luhmann ${ }^{12}$. A contribuição de Luhmann, nesse sentido, como já atestou o jurista brasileiro Aurélio Wander Chaves Bastos (2012), foi demonstrar que o direito precisa ter capacidade de absorver o processo de ampliação da complexidade social, mas, para que não pereça, precisa observar sua autopoiese ${ }^{13}$, ou seja, o direito deve preservar seu caráter contingencial e sua capacidade de se autoproduzir.

O estudo da obra de Luhmann (2002) permite visualizar o direito como um subsistema social, que tem como operação constitutiva a comunicação e que é parte do sistema social, a sociedade. A sociedade atual, objeto de descrição e observação de 
Luhmann (1990), é hipercomplexa, policontextural ${ }^{14}$ e diferenciada por funções. Diante da grande complexidade que caracteriza a sociedade moderna, os subsistemas se especializam e se afirmam por meio do desempenho de funções sociais específicas. Assim, a sociedade foi se diferenciando internamente de maneira a reduzir complexidade e, paradoxalmente, aumentou complexidade com a criação de subsistemas com funções específicas. Cada função desempenhada pelos subsistemas sociais (política, economia, direito, ciência, educação, arte, religião, família ${ }^{15}$ ) visa resolver um problema comunicacional específico. A função do direito pode ser compreendida como manter com estabilidade as expectativas comunicativas ainda que violadas. Essas expectativas são mantidas graças às normas que se mantém estáveis mesmo quando violadas.

O direito é um sistema autopoiético, que é operativamente fechado e cognitivamente aberto (cf. LUHMANN, 2002). A clausura do sistema significa que ele se diferencia de seu ambiente e tem operações referidas a si mesmo que não se confundem com eventuais operações do ambiente. Essa recursividade (auto referência) é o que permite concluir que é o próprio sistema que determina o que pertence a si mesmo. A abertura cognitiva do sistema, por sua vez, permite que o direito se abra ao seu ambiente por meio do acoplamento estrutural que possibilitará, por exemplo, a alteração das normas jurídicas. No entanto, o ambiente não pode intervir constantemente no sistema, pois o sistema entraria em corrupção, deixando de operar com o seu próprio código e, consequentemente, tornando-se indiferenciado de seu ambiente. Como subsistema que resolve conflitos ao mesmo tempo que gera outros, o direito utiliza-se do código binário lícito/ilícito (Recht/Unrecht) ${ }^{16}$ e esse código é que garante a clausura do sistema. Assim, as demandas apresentadas ao direito serão processadas em conformidade com esse código: o direito irá apontar quem está juridicamente com a razão e quem não está, em cada situação que lhe seja apresentada.

Por fim, há que se reconhecer com Luhmann (2002), que o direito combina normatividade e conhecimento. O direito garante estabilidade (pois as normas continuam vigentes mesmo quando são violadas) e capacidade de aprender (pois recebe novas controvérsias vindas do exterior do sistema jurídico e precisa ser capaz de processá-las de acordo com seu código interno). Assim, o direito precisa preservar sua especificidade por meio do seu fechamento estrutural, sem deixar de ter abertura cognitiva ao exterior de modo a comunicar-se com os demais sistemas da sociedade. 
A constitucionalização e a refundação da Teoria do Direito: novos dilemas

Nesse sentido, o ensinamento da teoria dos sistemas sociais de Luhmann à Teoria do Direito é de que se faz necessário preocupar-se em responder aos novos conflitos sociais que lhe são apresentados, sem perder de vista, porém, a exigência de manter sua recursividade e clausura operativa - elas lhe possibilitam manter-se como um subsistema social ao mesmo tempo dependente dos demais subsistemas sociais, porém, diferenciado do seu entorno.

\section{CONSIDERAÇÕES FINAIS}

O formalismo jurídico que caracterizou a Teoria do Direito do século XIX entendia que o Direito seria completo, de que haveria uma regra para cada caso (coerência e exatidão) e que essa regra poderia ser interpretada de forma clara e também uniforme. Como visto, essa perspectiva, que não se confunde com o positivismo jurídico, fundamentava boa parte da dogmática jurídica.

Com o processo de constitucionalização, os sistemas jurídicos renderam homenagem tardia a Hans Kelsen, consagrando o controle de constitucionalidade de modo a compatibilizar as leis infraconstitucionais com a Constituição e, assim, limitar o poder do legislador ordinário. Mas o processo de constitucionalização que se seguiu à Segunda Guerra mundial foi além de buscar um limitador para o poder legislativo, buscou consagrar os direitos fundamentais como fundamento infundado de toda ordem jurídica e, assim, servir como um limite a toda e qualquer manifestação do poder. Tratava-se da tentativa de harmonizar vontade popular e respeito aos direitos humanos. Reconhece-se, assim, a cultura dos direitos humanos, a limitação do poder e a convivência civilizada, como a consolidação do patrimônio comum da humanidade.

Nesse novo contexto, a Constituição e os direitos fundamentais adquirem papel central na ordem jurídica, de um Estado de Direito passa-se ao Estado Constitucional, em que as leis são, muitas vezes, fonte de instabilidade e a Constituição o fator de estabilização do sistema. O direito passa a ser um direito dúctil (ZAGREBELSKY, 2011), maleável, em constante adaptação diante do pluralismo político e de valores da sociedade. A maleabilidade do direito se traduz na distinção entre princípios e regras. Na perspectiva de Ronald Dworkin, os princípios permitem aproximar o direito da moral, ou ainda, compreender que não estão separados, pois eles referem-se à fins e valores. As regras possuem fórmulas rígidas de aplicação e, em caso de choque com outras que lhes sejam contraditórias, devem ser excluídas do sistema 
(invalidade). Já os princípios convivem, no mesmo sistema, com outros que lhe sejam contrários e, conforme as circunstâncias fáticas e jurídicas do caso concreto, devem ceder ou ser aplicados. Em sentido semelhante, Robert Alexy afirma que a distinção entre princípios e regras é qualitativa, sendo os princípios mandatos de otimização que devem ser realizados na maior medida possível.

A partir dessa diferenciação, Zagrebelsky (2011) afirma que as leis são regras e os princípios correspondem à Constituição. No Estado Constitucional, os juízes assumem assim posição central, pois a interpretação subsuntiva (defendida pelo formalismo) dá lugar a uma interpretação criativa por parte do Juiz.

A partir dessa questão pudemos visualizar o primeiro dilema que se apresenta para a Teoria do Direito após a constitucionalização: o subjetivismo da decisão judicial. Na tentativa de lidar com esse dilema e limitar o poder decisório dos juízes, a Teoria do Direito caminha em dois sentidos. O primeiro é institucional, inspirado no jurista francês Michel Troper (2005) e com José Rodrigo Rodriguez (2011), chamamos esse modelo de "constrangimentos institucionais" em que se busca alcançar congruência nas decisões judiciais controlando o recrutamento dos juízes e estabelecendo uma estrutura do poder Judiciário e procedimentos que possibilitem a uniformização jurisprudencial. De outro lado, a segunda proposta é hermenêutica, buscam-se modelos hermenêuticos que exijam dos magistrados a exposição fundamentada e racional de suas decisões de modo a possibilitar o controle.

Nesse sentido, expôs-se a visão de José Rodrigo Rodriguez (2012), de que a segurança jurídica implica em novos contornos, não se trata de buscar uma única resposta, mas de compreender que o fundamental é a explicitação dos argumentos racionais. A fundamentação racional é que possibilitará o controle interno da decisão (dentro do direito, por exemplo, por meio do sistema de recursos) e também responderá à necessidade de legitimidade política dessa decisão (frente à coletividade).

A ideia da segurança jurídica como racionalidade e possibilidade de controle permite manter o sistema jurídico aberto e receptivo às novas demandas que lhe são apresentadas. Mas justamente nessa abertura se encontra o segundo dilema da Teoria do Direito pós-constitucionalização: a questão da manutenção da autonomia do direito. $\mathrm{O}$ direito não pode se abrir de tal maneira à moral, economia e política, por exemplo, de modo a perder sua especificidade. A partir da teoria dos sistemas de Niklas Luhmann (2002) pode-se compreender o caráter estruturalmente fechado, mas 
A constitucionalização e a refundação da Teoria do Direito: novos dilemas

cognitivamente aberto do sistema jurídico, como características importantes para que ele mantenha diferenciado com relação seu meio.

Ao final, a exposição dos novos dilemas da Teoria do Direito nos permite compreender as transformações pelas quais ela passou, sem, no entanto, ignorar que os dilemas são seus desafios, não resolvidos definitivamente.

\section{REFERÊNCIAS}

ALEXY, Robert. Teoria dos Direitos Fundamentais. Trad. Virgílio Afonso da Silva. 5. ed. São Paulo: Malheiros, 2008.

BARROSO, Luís Roberto. Neoconstitucionalismo e constitucionalização do direito (o triunfo tardio do direito constitucional no Brasil). In: SOUZA Neto, Cláudio Pereira; SARMENTO, Daniel (orgs.). A constitucionalização do direito. Rio de Janeiro: Lumen Juris, 2007, p. 203-249.

Curso de Direito Constitucional Contemporâneo: os conceitos fundamentais e a construção do novo modelo. 4 ed. São Paulo: Saraiva, 2013.

BASTOS, Aurélio Wander Chaves. O Conceito de Direito e As Teorias Jurídicas da Modernidade. Jurispoiesis, Rio de Janeiro, p. 37-56, 1999.

BOBBIO, Norberto. A era dos direitos. Trad. Carlos Nelson Coutinho. Rio de Janeiro: Elsevier, 2004.

O positivismo jurídico: lições de Filosofia do Direito. São Paulo: Ícone, 2006.

Teoria geral do direito. São Paulo: Martins Fontes, 2010.

CARDUCCI, Michele. Tra diritto costituzionale «generale» e diritto costituzionale «comune». In: Alle frontiere del diritto costituzionale. Scritti in onore di Valerio Onida, Milano, Giuffrè, 2011, p. 347-362.

; BRUNO, A.S. Studying the Legal Flows as a Multidisciplinary Method to Promote Constitutionalism as a Common Property of Mankind. European Scientific Institute-ESI, I vol., Republic of Macedonia, Kocani, 2013.

COMANDUCCI, Paolo. Formas de (neo)constitucionalismo: un análisis metateórico. In: CARBONELL, Miguel (Org.). Neoconstitucionalis-mo(s). Madrid: Editorial Trotta, 2003, p. 75-98.

COSTA, Pietro. Soberania, Representação, Democracia: ensaios de história do Pensamento Jurídico. Curitiba: Juruá, 2010.

CUBEIRO, Manuel Torres. Niklas Luhmann. Coruña: Baía Edicións, 2008. 
DIMOULIS, Dimitri. Positivismo Jurídico: introdução a uma teoria do direito e defesa do pragmatismo jurídico-político. São Paulo: Método, 2006.

; MARTINS, Leonardo. Teoria Geral dos Direitos Fundamentais. 3 ed. São Paulo: Editora Revista dos Tribunais, 2011.

DWORKIN, Ronald. Levando os direitos a sério. São Paulo: Martins Fontes, 2002.

FARALLI, Carla. A filosofia contemporânea do direito: temas e desafios. São Paulo: WMF Martins Fontes, 2006.

GARCIA AMADO, Juan Antonio. Principios, reglas y otros misteriosos pobladores del mundo jurídico. In: Pablo Raúl Bonorino Ramírez (Editor). Teoría del derecho y decisión judicial. Espanha: Bubok Publishing, 2010, p. 285-343.

. Derechos y pretextos. Elementos de crítica del neoconstitucionalismo. In: CARBONELL, Miguel (Org.). Teoria del neoconstitucionalismo. Madrid: Editorial Trotta, 2007, p. 237-264.

HART, Herbert L. A. O conceito de direito. São Paulo: Editora WMF Martins Fontes, 2009.

HESPANHA, António Manuel. $O$ caleidoscópio do direito: O direito e a justiça nos dias e no mundo de hoje. 2 ed. Coimbra: Almedina, 2014.

HESSE, Konrad. A Força Normativa da Constituição. Porto Alegre, Editora Sérgio Antônio Fabris, 1991.

KELSEN, Hans. Teoria Pura do Direito. 6ª ed. São Paulo: Martins Fontes, 1998.

LAFER, Celso. Apresentação. In: BOBBIO, Norberto. A era dos direitos. Rio de Janeiro: Elsevier, 2004.

LUHMANN, Niklas. Sociedad y sistema: la ambición de la teoria. Barcelona: Ediciónes Paidós Ibérica, 1990.

El derecho de la sociedad. Tradução de Javier Torres Nafarrate. México: Universidad Iberoamericana, 2002.

NEVES, Marcelo. Entre Hidra e Hércules: Princípios e Regras constitucionais como diferença paradoxal do sistema jurídico. São Paulo: WMF Martins Fontes, 2014.

RODRIGUEZ, José Rodrigo. Como decidem as cortes - para uma crítica do direito (brasileiro). São Paulo: Editora FGV, 2013.

Por um Novo Conceito de Segurança Jurídica: Racionalidade Jurisdicional e Estratégias Legislativas. Analisi e diritto, Madrid, Barcelona, Buenos Aires, São Paulo: Marcial Pons, p. 129-152, dez. 2012.

. Zonas de Autarquia nas decisões jurisdicionais: Estado de Direito, 
indeterminação e democracia, In: VILHENA, Oscar Vieira; DIMOULIS, Dimitri. O Estado de Direito e os Desafios do Desenvolvimento, São Paulo: Saraiva, 2011.

STRECK, Lênio. O que é isto - decido conforme minha consciência? Porto Alegre: Livraria do Advogado Editora, 2013.

TROPER, Michel; CHAMPEIL-DESPLATS, Véronique; GRZEGORCZYK, Christophe (Org.), Théorie des contraintes juridiques. Paris: LGDJ 2005.

WARAT, Luís Alberto. Saber crítico e senso comum teórico dos juristas. Seqüência. UFSC, Florianópolis, SC, v. 3, n. 5, 1982.

ZAGREBELSKY, G. El derecho ductil. Ley, derechos y justicia. 10a ed. Trad. Marina Gascón. Madrid: Trotta, 2011.

ZWEIG, Stefan. Autobiografia: o mundo de ontem. Rio de Janeiro: Zahar, 2014.

Artigo recebido em 26 de janeiro de 2018 e aceito em 31 de dezembro de 2018

\footnotetext{
${ }^{1}$ Como aponta Zweig em seu vivo relato: "Os poucos dentre os escritores que realmente tinham se dado ao trabalho de ler o livro de Hitler ironizavam o estilo pomposo de sua prosa em vez de se ocupar com o seu programa. No lugar de alertar, os grandes jornais democráticos tranquilizavam os seus leitores todos os dias dizendo que aquele movimento, que realmente só com muito esforço financiava sua enorme agitação com recursos da indústria pesada e ousadas dívidas, estaria fadado a ruir inevitavelmente amanhã ou depois de amanhã. [...] E mesmo quando ele, naquele dia de janeiro em 1933, se tornou chanceler, a grande multidão e até os que o empurravam para esse posto consideravam-no apenas um ocupante provisório do cargo, e o domínio nacional-socialista, um mero episódio. E, afinal, que violências ele poderia praticar numa nação em que o direito estava firmemente arraigado, em que, no Parlamento, a maioria estava contra ele e cada cidadão julgava garantidas sua liberdade e igualdade de direitos, com base na Constituição solenemente jurada? Então, aconteceu o incêndio do Reichstag, o Parlamento desapareceu, Göring soltou seus bandos, de um golpe foi destruído todo o direito na Alemanha. Horrorizados, ouvimos que havia campos de concentração em plena paz e que nas casernas tinham sido construídos compartimentos secretos em que pessoas inocentes eram eliminadas sem tribunal ou formalidades. Isso só podia ser um surto de uma primeira ira insensata, dizia-se. Algo assim não podia perdurar no século XX. Mas foi apenas o começo. $\mathrm{O}$ mundo escutava e a princípio não queria acreditar no inacreditável. Mas já naqueles dias vi os primeiros fugitivos. De noite, haviam transposto as montanhas de Salzburgo ou cruzado o rio da fronteira a nado. Esfomeados, esfarrapados, olhavam para nós cheios de medo; foi o início da fuga em pânico ante a desumanidade que depois se estendeu pelo mundo todo. Porém, ao ver esses exilados, eu ainda não imaginava que seus rostos pálidos anunciavam o meu próprio destino e que todos seríamos vítimas da mania de poder desse único homem". (ZWEIG, 2014, p. 321-323.)
} 
${ }^{2}$ Os direitos fundamentais podem ser compreendidos como "direitos público-subjetivos de pessoas (físicas ou jurídicas), contidos em dispositivos constitucionais e, portanto, que encerram caráter normativo supremo dentro do Estado, tendo como finalidade limitar o exercício do poder estatal em face da liberdade individual.” (DIMOULIS, MARTINS, 2011, p.41). Essa conceituação apresenta o caráter de fundamentalidade relacionado à sua positivação constitucional e também ao seu papel de limitador do arbítrio estatal frente à liberdade. No entanto, outros autores enfatizam não somente sua previsão constitucional, mas apontam como seu núcleo a proteção da dignidade da pessoa (cf. MENDES, COELHO, BRANCO, 2008, p. 231) ou consideram que a dignidade humana é a justificação moral e o fundamento normativo dos direitos fundamentais (cf. BARROSO, 2013).

${ }^{3} \mathrm{O}$ termo neoconstitucionalismo é plurissêmico possuindo distinções conforme o autor que se considere como neoconstitucionalista, optou-se, no trabalho, por utilizar a definição de Comanducci (2003) do neoconstitucionalismo como Teoria do Direito e do Estado.

${ }^{4}$ Para uma crítica do pós-positivismo e do neoconstitucionalismo, ver: DIMOULIS, 2006.

${ }^{5}$ Sobre o tema conferir, por exemplo, o texto de Bobbio (2006, p. 37ss).

${ }^{6}$ É importante dizer ainda que o formalismo assim caracterizado não se confunde com o positivismo jurídico. Bobbio (2006, p. 237), por exemplo, trata do positivismo em sentido estrito que teria como pilastras a teoria coativa, legislativa e imperativa do direito. Já o positivismo em sentido amplo, além dessas três bases, sustentaria também as ideias de coerência, completude e interpretação lógica e mecanicista do direito. Assim, autores como Hans Kelsen (1998), que é um dos maiores nomes do positivismo, negam veementemente a teoria da interpretação mecanicista, Kelsen (1998) defende que o ato interpretativo do direito pelo juiz é valorativo e, portanto, criativo.

7 Zagrebelsky (2011, p. 13) assim caracteriza nossas sociedades plurais: "marcadas por la presencia de una diversidade de grupos sociales con interesses, ideologias y proyectos diferentes, pero sin que ninguno tenga fuerza suficiente para hacerse exclusivo o dominante y, por tanto, estabelecer la base material de la soberania estatal en el sentido del passado."

8 "La ley, en suma, ya no es garantía absoluta y última de estabilidad, sino que ella misma se convierte en instrumento y causa de inestabilidad. Las consecuencias de la ocasionalidad de las coaliciones de intereses que ella expresa se multiplican, a su vez, en razón del número progresivamente creciente de intervenciones legislativas requeridas por las nuevas situaciones constitucionales materiales." (ZAGREBELSKY, 2011, p. 38).

${ }^{9}$ Dworkin distingue os princípios de políticas: "Denomino 'política' aquele tipo de padrão que estabelece um objetivo a ser alcançado, em geral uma melhoria em algum aspecto econômico, político ou social da comunidade (ainda que certos objetivos sejam negativos pelo fato de estipularem que algum estado atual deve ser protegido contra mudanças adversas). Denomino 'princípio' um padrão que deve ser observado, não porque vá promover ou assegurar uma situação econômica, política ou social considerada desejável, mas porque é uma exigência de justiça ou equidade ou alguma outra dimensão da moralidade. Assim, o padrão que estabelece que os acidentes automobilísticos devem ser reduzidos é uma política e o padrão segundo o qual nenhum homem deve beneficiar-se de seus próprios delitos é um princípio." (DWORKIN, 2002, p. 36).

10 “[...] a los principios, a diferencia de lo que sucede con las reglas, sólo se les puede dar algún significado operativo haciéndolos "reaccionar" ante algun caso concreto. Su significado no 
puede determinarse en abstracto, sino sólo en los casos concretos, y sólo en los casos concretos se puede entender su alcance." (ZAGREBELSKY, 2011, p. 111).

11 "No lugar do ideal de uma resposta jurídica única para cada tipo de conflito jurídico, a obtenção de respostas bem fundamentadas, não arbitrárias, que explicitem seus fundamentos para que seja possível discuti-los e submetê-los a algum grau de formalização e padronização." (RODRIGUEZ, 2012, p. 146).

${ }^{12}$ Luhmann herdou de Talcott Parsons, de quem foi aluno em Harvard, a preocupação em criar uma teoria explicativa da sociedade em sua totalidade (cf. CUBEIRO, 2008). Luhmann visualizou que o funcionalismo estrutural de Parsons e sua teoria da ação pareciam oferecer novas possibilidades para o melhor entendimento da sociedade. Entretanto, a limitação da proposta de Parsons está em partir da existência de estruturas nos sistemas sociais, mas não questiona a função da própria estrutura, o que dificulta a explicação da mudança social, da história. A sociologia deve dar conta dessa complexidade multiplicada e na teoria dos sistemas de Luhmann faz-se possível fazer indagações sem considerar causas unívocas. Luhmann vai além de Parsons e concebe o social como em constante mutação, como contingente e não ontologicamente constante (cf. CUBEIRO, 2008, p. 42).

13 A autopoiése (autopoiesis), característica dos sistemas biológicos, de Maturana e Varela utilizada por Luhmann, corresponde a capacidade que possuem os sistemas de produzir e reproduzir por si mesmos todos os elementos que os constituem. Dessa forma os sistemas definem por si mesmos a sua própria unidade, mas processam a sua operação de autocriação como se independentes do entorno, apesar de dependerem deste (cf. CUBEIRO, 2008, p. 44).

${ }^{14}$ Cada subsistema funciona de acordo com um código binário próprio, que não aceita as distinções dos demais subsistemas. A policontexturalidade indica que existem vários códigos com validez simultânea, ainda que se rejeitem entre si (CUBEIRO, 2008, p. 103).

${ }^{15}$ Ao sistema político compete possibilitar à sociedade a capacidade de decidir de um jeito coletivamente vinculante. Já a economia nasce do paradoxo da escassez, pois ao intencionar eliminar escassez por meio de acesso aos bens, aumenta a escassez. A arte, enquanto subsistema social, por sua vez, é encarregada de oferecer ao mundo a possibilidade de observar a si mesmo por meio de possibilidades excluídas, opera sempre a partir de uma observação de segunda ordem. Cumprindo sua função a religião nos fala de Deus, do além, tratando de fazer comunicável o fato de que ao lado do observável existe sempre algo que nos foge a observação. A difícil tarefa do subsistema da educação, por sua vez, é induzir mudanças nos sistemas psíquicos particulares para que participem da comunicação na sociedade hipercomplexa e policontextural. Também com a tarefa de influenciar os sistemas psíquicos e mais ainda os sistemas vivos, o subsistema da saúde tem a função de curar os enfermos ou seja, interferir quando um indivíduo não está em condições de ser uma base orgânica ou psíquica para a comunicação. Finalmente, ao sistema da ciência compete construir e obter conhecimento, operando com o meio de comunicação simbolicamente generalizado da verdade e o código binário verdadeiro/não verdadeiro (CUBEIRO, 2008, p. 104-118).

${ }^{16}$ A tradução do código Recht/Unrecht apresenta-se problemática. Há opções por direito/não direito, conforme ao direito/não conforme ao direito, lícito/ilícito, legal/ilegal. A advertência de Javier Torres Nafarrate (em nota de rodapé na tradução ao castelhano de LUHMANN, Niklas. El derecho de la sociedad, 2002, p. 81) é no sentido de que a expressão em alemão tem maior abrangência do que seus possíveis equivalentes em castelhano (o que entendo também acontecer na tradução para o português), pois nem todas as questões jurídicas guardam relação com a conformidade ou não conformidade ao direito (lícito/ilícito, legal/ilegal), mas muitos casos se dão no sentido de que o direito por um lado se define com relação a um não direito. Entretanto, 
em seu Workshop ministrado no Congresso Internacional em Homenagem a Cláudio Souto Sociedade, Direito e Decisão em Niklas Luhmann (24 a 27 de novembro de 2009, Recife-PE, UFPE), Marcelo Neves sustentou que o mais adequado seria se utilizar da tradução lícito/ilícito, tendo em vista que se trata de uma distinção interna do direito, pois o "não direito" estaria fora do direito e não seria cabível nessa distinção. Optou-se aqui por, considerando a advertência de Marcelo Neves, fazer uso da tradução lícito/ilícito. 